\title{
The User Centred Design (UCD) and User Experience Design (UXD) Practice In Industry: Performance Methods and Practice Constraints
}

\author{
Idyawati Hussein, Azham Hussain, Emmanuel O.C.Mkpojiogu, ZarulFitri Zaba
}

\begin{abstract}
This study reviews the methods used in investigating user centred design (UCD) practice in industry as well as the constraints to the practice of UCD and user experience design $(U X D)$ in industry using systematic literature review approach. Thirty-five high profile papers were reviewed and the result showed that among others, low-profile usability professionals in the development process, usability not being accepted as a key quality, usability not supporting product development time, resistance to usability, lack of awareness, and time constraints are the constraints facing UCD and $U X D$ in practice. Most software development studies also found constraints between developers and users. The study's outcome also revealed that most investigations carried out to assess UCD/UXD practice was done using surveys (66\%) followed by interviews (29\%).
\end{abstract}

Keywords: Investigative methods, User centred design, User experience design, $U X D$ practice constraints

\section{INTRODUCTION}

This study provides the systematic literature review (SLR) conducted to address the issues confronting user centred design (UCD)and user experience design (UXD) in practice. Constraints to UCD and UXD were then discussed and themes created. Methods used in identifying constraints in the literature were also captured and summarized. The systematic literature review (SLR) was undertaken: (1) to summarise the existing evidence concerning usability and user experience in industry practice; (2) to identify constraints and reasons for the reluctance of companies to practise UCD or recognise the importance of user experience; (3) to identify as much information as possible with regards to the research approach used when studying UCD or UXD practice in industry settings (Silva da Silva et al., 2011). The reason for conducting a SLR was to avoid the personal, subjective and biased traditional narrative approach to literature reviews (Salleh et al., 2010). There has been a pattern of study to identify the subject of inquiry for industry practice since 1983.

Revised Manuscript Received on June 22, 2019.

Idyawati Hussein, School of Computing, Universiti Utara Malaysia, 06010 UUM, Sintok, Malaysia

Azham Hussain, School of Computing, Universiti Utara Malaysia, 06010 UUM, Sintok, Malaysia

Emmanuel O.C.Mkpojiogu, School of Computing, Universiti Utara Malaysia, 06010 UUM, Sintok, Malaysia, Department of Computer and Information Technology, Veritas University, Abuja, Nigeria

ZarulFitri Zaba, School of Computer Sciences, UniversitiSains Malaysia, 11800 Minden, Pulau Pinang, Malaysia
Rauch and Wilson (1995) surveyed the members of the User Experience Professionals Association (UxPA), formerly known as the Usability Professionals Association (UPA), in 1991 and 1992. The result was then presented at the UPA conference in 1993. Another round of practice surveys was done with the UPA mailing list in 1993. A follow-up survey was conducted at a Special Interest Group (SIG) session at the CHI'94 conference in the form of interactive, face-toface meetings with open discussions of key questions. Later, Rosebaum et al. (2002) studied the evolution and revolution of the user experience lifecycle in practice by surveying the members attending CHI'98, CHI'99 and UPA'99 conferences. In addition, Mao et al. (2005) surveyed identical respondents during the $\mathrm{CHI} 02$ and UPA'02 conferences. Also, Ronggang et al. (2008) distributed an online survey to the UPA China members' mailing, list following a survey at the UPA China's User Friendly Conference in 2007, the target respondents being people who attended human factors and/or HCI talks (Gould \& Lewis, 1985). According to Karat (1996), people attending a conference on human factors in computer systems would be expected to have a united view of UCD principles. Furthermore, given the fact that they attended the CHI conference and were members of UPA, it would be reasonable to believe that they were playing leading roles in the UCD community or at least had familiarity with UCD (Mao et al., 2005).

\section{METHODOLOGY}

Two important steps taken are the setting of the inclusion criteria and the strategy of locating and selecting potential studies (Higgins, 2008). The following strategy was used to construct the search terms. First, the primary studies were identified by using a search string on Google Scholar. There are four criteria in creating a search string: population, intervention, comparison and outcomes (Kitchenham\& Charters, 2007; Higgins, 2008).

Table 1: Keywords used in the review process

\begin{tabular}{|l|l|}
\hline Population & User experience \\
\hline Interventions & Integrate UCD \\
\hline Comparisons & $\begin{array}{l}\text { Constraints, research } \\
\text { methods, approach }\end{array}$ \\
\hline Outcomes & UCD, industry practice \\
\hline
\end{tabular}


Table 1 lists keywords used in the review process. The focus of the review was on professionals whose job is to produce usable and good user experience products, and whose job titles include user experience professional, HCI practitioner or usability engineer among others. Articles published by Association for Computing Machinery (ACM) are highly respected and listed on their HCI Bibliography: HCI Resources website (SIGCHI, 2015). The search was a combination of "HCI" and "User Experience" practice. $\mathrm{HCI}$ and user experience are heterogeneous and terms such as
UCD, user experience design, usability and interaction are used with a similar meaning (Silva da Silva et al., 2011; Putnam et al., 2012). The term "usability engineer" was added as the focus of these personnel was to produce usable systems; this job has existed since the 1980s (Gould \& Lewis, 1985; Gulliksen et al., 2001; Bygstad et al., 2008; Clemmensen et al., 2013; Hashim et al., 2017). The term "UCD" and "HCD" were used interchangeably (Tullis \& Albert, 2013). Hence, both terms were included in the search procedure, as illustrated in Table 2.

Table. 2 Keywords search based on Google Scholar

\begin{tabular}{|l|l|}
\hline Find articles & Rules \\
\hline With all of the words & $\begin{array}{l}\text { UCD Practice OR User Experience Design OR Usability Engineering OR Interaction } \\
\text { Design Practice OR }\end{array}$ \\
\hline With the exact phrase & User Centred Design Practice \\
\hline With at least one of the words & Designers OR Developers OR Development OR Practitioners OR Usability OR Engineer \\
\hline Excluding & Agile, Book \\
\hline
\end{tabular}

During the initial search, a very large number of irrelevant papers were retrieved, consisting of applications of UCD in other domains. To avoid any bias, these were included in the first round of the study. The second stage included screening the papers for either inclusion or exclusion. During this stage, papers were selected for their real-world context as opposed to simulated environments, for instance, using student groups as substitute users. The application of UXD or UCD in other specific domains was not considered further in the search. The abstracts of the papers were briefly scanned and eliminated if they were book titles and reported on the application of UCD in other domains such as Agile, healthcare or gaming. Books were eliminated because the objective of this study was to identify the constraints of UXD practice (which excludes the matured information in books). Agile is considered a method that supports iterative activities. However, Agile itself is not a UX process. To include a paper in the analysis, it must have been written in English, and have been peer-reviewed. Papers published in academia.edu were not included as some of them were not peer-reviewed. The digital library sources selected for the search were: i. Scopus (because it covered ACM and Springer), ii. Elsevier, iii. Science Direct, iv. Wiley International, and v. IEEE Digital Library.

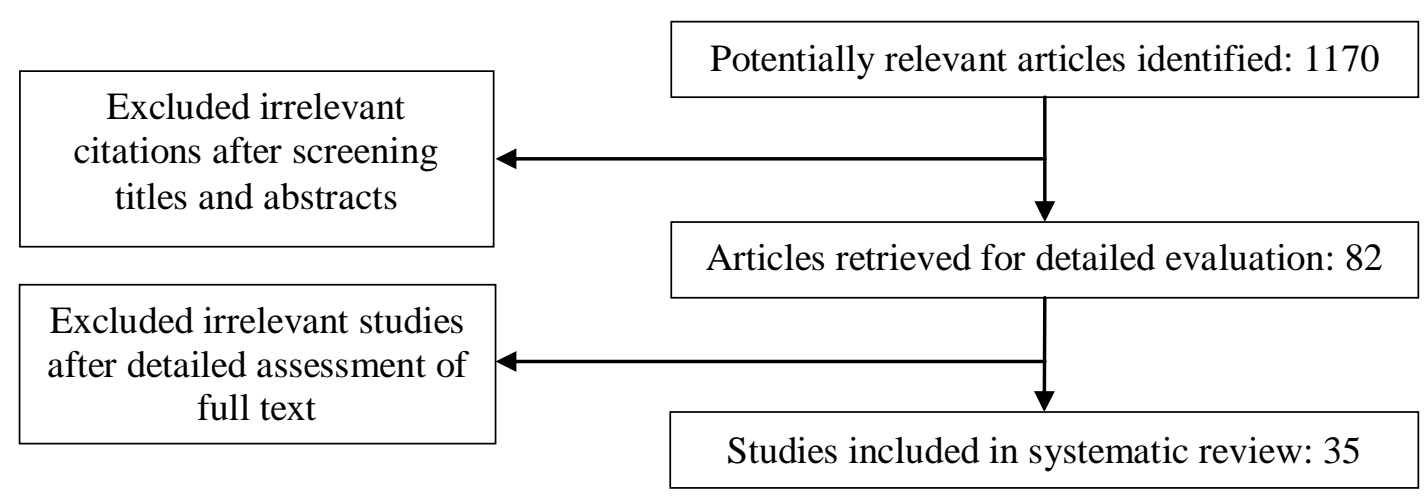

Fig. 1 Selection Strategy for UXD in practice study

The third stage was to retrieve articles based on the selected online databases. Irrelevant studies were excluded after a detailed assessment of the full text. This includes studies that were not based on industry practices or studies that included university students as the subject of experiment. The fourth stage was to extract and map the articles on the practice of usability and user experience, to uncover issues and to identify research methods used in discovering usability and user experience practice in industry settings. At the beginning of this study, the first combination of key terms used in the search was "HCI practice $<\mathrm{OR}>$ usability $<\mathrm{OR}>$ user experience". It was found that the terminology used for the process referred to $\mathrm{HCI}$ and the achievement of usability and/or user experience referred to UCD. The search keywords were changed accordingly and resulted in a return of some 1,170 articles.
After screening the titles and abstracts, the irrelevant citations were excluded, leaving 82 articles to be screened for titles and abstracts. 35 articles were eventually included in the SLR for detailed evaluation.

Figure 1 shows the process of finalising the studies to be included in the final review, which consists of keywords and concepts that reflect the contribution of each paper. This takes into account the basis of the context of research which has been identified as industry practice. The search phase involved the process of identifying relevant literature related to the selected keywords. 
The initial phases of the search process involved distinguishing primary sources based on the HCI Bibliography official website. The sources of the papers were classified into five categories of HCI publications: first choice (top resources in publications); ACM SIGCHI (304); columns (36); digital library (57); journals (62) and publishers (33). In total, the primary electronic databases contained 139 links.

\section{RESULTS}

Figure 2 shows the result of 35 articles identifying constraints in UCD practice. The pioneers who studied the practice of UCD believed that a process is needed to achieve usability goals (Hammond et al., 1983; Gould \& Lewis, 1985). 22 out of 35 articles on industry practice were conducted by online and questionnaire surveys (66\%). Targeted samples of the studies were conference attendees and UPA members. The complexity of the real world which is full of many uncontrolled variables and often contradictory to the behaviour of the scientist leads to constraints of conducting research in practice (Rosenbaum et al., 1999; Norman, 2010; Chaiklin, 2011).The second highest methods in UCD practice approach was interview (29\%), and the first article included in this review was published in 1983. Hammond et al. (1983) reported the behaviour of design practitioners towards useful design. It was very rare that a researcher focused on behaviour rather than descriptions of practitioners of their own interface design. Using an interview method, the researchers were trying to uncover the way usability was being practised in the real world. The term "user experience" first appeared in the article published in 1983 and was first coined in 1995 by Norman (Hammond et al., 1983; Ibargoyen et al., 2013). However, the concept had been used during product design and development processes since the late 1990s (Forlizzi\& Ford, 2000). Early in the history of the profession, "user" was the term used to denote the stakeholder group that interacted with the system to attain some goal, who had little interest in the system that achieved that goal, and who had little interest in, or knowledge about, the technology itself (Clemmensen et al., 2013). Grudin (1991) disagreed with the term "user" at first because it refers to a drug addict from a layman's perspective. From the aspect of users, the term user and end user are normally used synonymously in most published materials. To avoid ambiguity, the distinction between the two should be identified. Users are all the people interacting with software systems, so even software engineers are users of the tools and environments that they use for their work; end users are people who are not expert in computer science, nor willing to be, but who use computer systems for their daily activities (Gulliksen et al., 1999; Ardito et al., 2011) (see Hussain et al., 2016; 2017a; 2017b; 2017c; 2018).

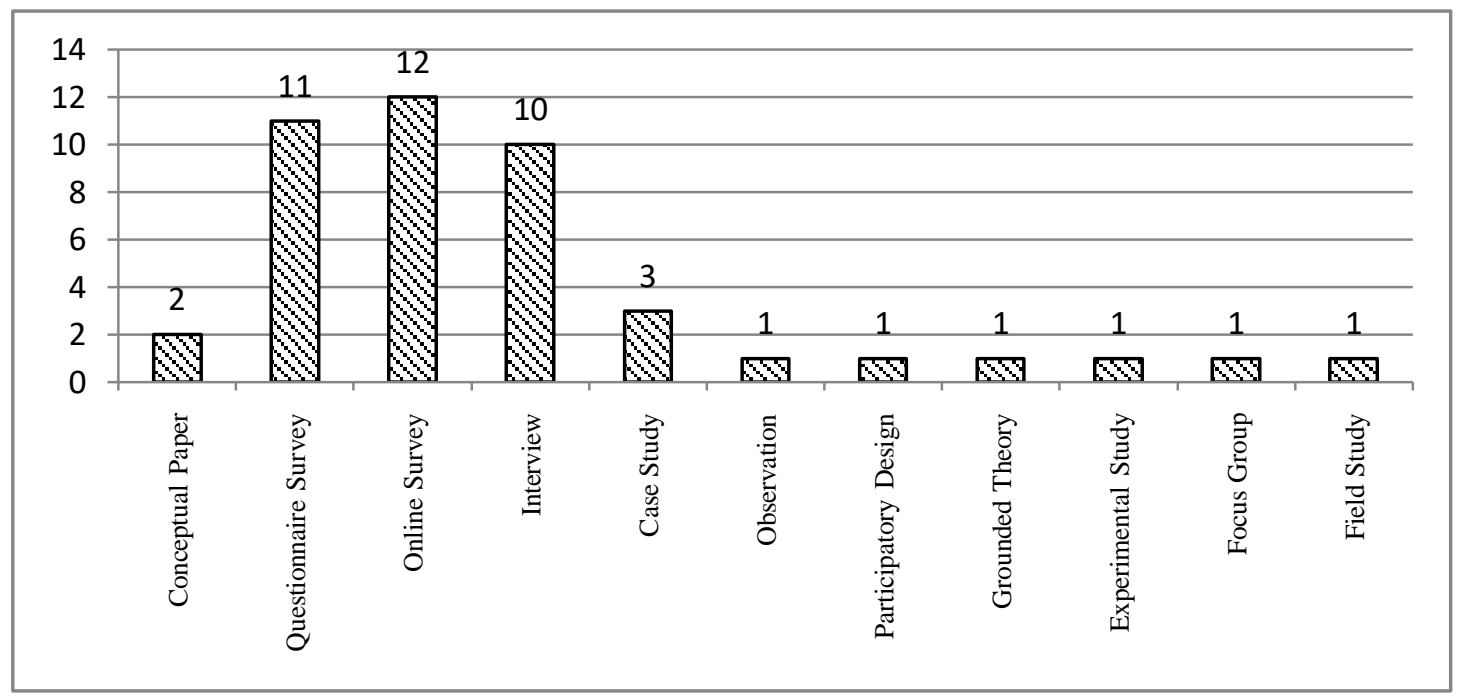

Fig. 2 Research methods used in articles reporting constraints and obstacles in UCD practice (1983 - 2013)

\section{Constraints in Practice}

In relation to UCD practices, among other constraints are low-profile usability professionals in the development process, usability not being accepted as a key quality, usability not supporting product development time, resistance to usability, lack of awareness, and time constraints (Gulliksen, 2001; Ardito et al., 2013). Most software development studies found constraints between developers and users (Grudin, 1991; Borgholm \& Madsen,
1999; Holmstrom\& Sawyer, 2011). For example, when users had trouble, the designers were sometimes tempted to think they were "unintelligent" (Gould \& Lewis, 1985; Ardito et al., 2013). This may be due to the gap within the structure of the organisation that inhibits developer and user from working together (Poltrock\&Grudin, 1994; Mayhew, 1999). Table 3 contains the list of the constraints identified in the 35 articles evaluated in SLR. 
The User Centred Design (UCD) and User Experience Design (UXD) Practice in Industry: Performance Methods and Practice Constraints

Table. 3 Constraints to practice UXD

\begin{tabular}{|c|c|c|}
\hline Authors/years & Categories & Concepts \\
\hline \multirow[t]{5}{*}{ Hammond et al., 1983} & Designer's logical analysis and idealized conceptual & Developer's mindset \\
\hline & Designer's compatibility with previous system & Developer's mindset \\
\hline & $\begin{array}{l}\text { Designer's view on design process rather than on detailed decision- } \\
\text { making }\end{array}$ & Values \\
\hline & Common sense theories of users & Values \\
\hline & Organizational and resource constraints & Culture \\
\hline \multirow[t]{3}{*}{ Butler, 1985} & $\begin{array}{l}\text { Better understanding of what's going on by all concerned-researchers, } \\
\text { managers, programmers, and HF professionals }\end{array}$ & Awareness \\
\hline & Objective should be operationally defined and empirically tested & Goals \\
\hline & User performance criteria need to be specified in the requirements & $\begin{array}{l}\text { User performance } \\
\text { document }\end{array}$ \\
\hline \multirow[t]{10}{*}{ Gould \& Lewis, 1985} & User diversity is underestimated & $\begin{array}{l}\text { UCD principles are } \\
\text { undervalued }\end{array}$ \\
\hline & User diversity is overestimated & $\begin{array}{l}\text { UCD principles are } \\
\text { undervalued }\end{array}$ \\
\hline & Belief that users do not know what they need & $\begin{array}{l}\text { UCD principles are } \\
\text { undervalued }\end{array}$ \\
\hline & Belief that my job does not require it or permit it & Job roles limitation \\
\hline & Belief in the Power of reason & Values \\
\hline & Belief that design guidelines should be sufficient & Values \\
\hline & Belief that good design means getting it right the first time & Values \\
\hline & Belief that the development process will be lengthened & Time limitations \\
\hline & Belief that iteration is just expensive fine-tuning & $\begin{array}{l}\text { UCD principles are } \\
\text { undervalued }\end{array}$ \\
\hline & Belief in the power of technology to succeed & Mental model \\
\hline \multirow[t]{3}{*}{ Goransson et al., 1987} & Local condition & Culture \\
\hline & Work organizations & Culture \\
\hline & Skills and experiences of personnel & Implicit skills \\
\hline \multirow[t]{4}{*}{ Curtis et al., 1988} & The thin spread of application domain & Situations \\
\hline & Fluctuating and conflicting requirement & $\begin{array}{l}\text { Requirements } \\
\text { gathering }\end{array}$ \\
\hline & Communication and coordination breakdown & Communication \\
\hline & $\begin{array}{l}\text { Projects must be aligned with company goals and affected by } \\
\text { corporate politics, culture and procedures }\end{array}$ & $\begin{array}{ll}\text { Culture } & \text { and } \\
\text { procedures } & \\
\end{array}$ \\
\hline \multirow[t]{3}{*}{ Grudin\&Poltrock, 1989} & High expectation & Mental model \\
\hline & Unfamiliarity with the support group's proper role & Job role \\
\hline & $\begin{array}{l}\text { Tendency to consult clients only on the most difficult problem or } \\
\text { other factors }\end{array}$ & Clients \\
\hline \multirow[t]{2}{*}{ Nielsen, 1993} & Intimidating & Frustrations \\
\hline & Many developers do not use usability engineering approach & Values \\
\hline \multirow[t]{2}{*}{ Bias \& Mayhew, 1994} & Too time consuming & Values \\
\hline & Expensive & Values \\
\hline \multirow[t]{4}{*}{ Poltrock\&Grudin, 1994} & Inability of interface designers to obtain access to users & User's inaccessible \\
\hline & $\begin{array}{l}\text { Prototyping tools that allow minor changes to be tested but that } \\
\text { constraints innovation }\end{array}$ & $\begin{array}{l}\text { Technology } \\
\text { constraints }\end{array}$ \\
\hline & $\begin{array}{l}\text { Resistance to iterative design that results from people noticing and } \\
\text { being affected by interface changes }\end{array}$ & $\begin{array}{l}\text { UCD principles } \\
\text { undervalued }\end{array}$ \\
\hline & $\begin{array}{l}\text { Lack of communication among those sharing responsibility for } \\
\text { different aspects of the interface }\end{array}$ & Communication \\
\hline \multirow[t]{2}{*}{ Rauch \& Wilson, 1995} & Lack of formal usability group & $\begin{array}{l}\text { No } \\
\text { practitioners }\end{array}$ \\
\hline & $\begin{array}{l}\text { Many companies are not willing to invest money in usability, } \\
\text { providing lip service only - they say it is important, but do not fund } \\
\text { the work }\end{array}$ & Values \\
\hline
\end{tabular}




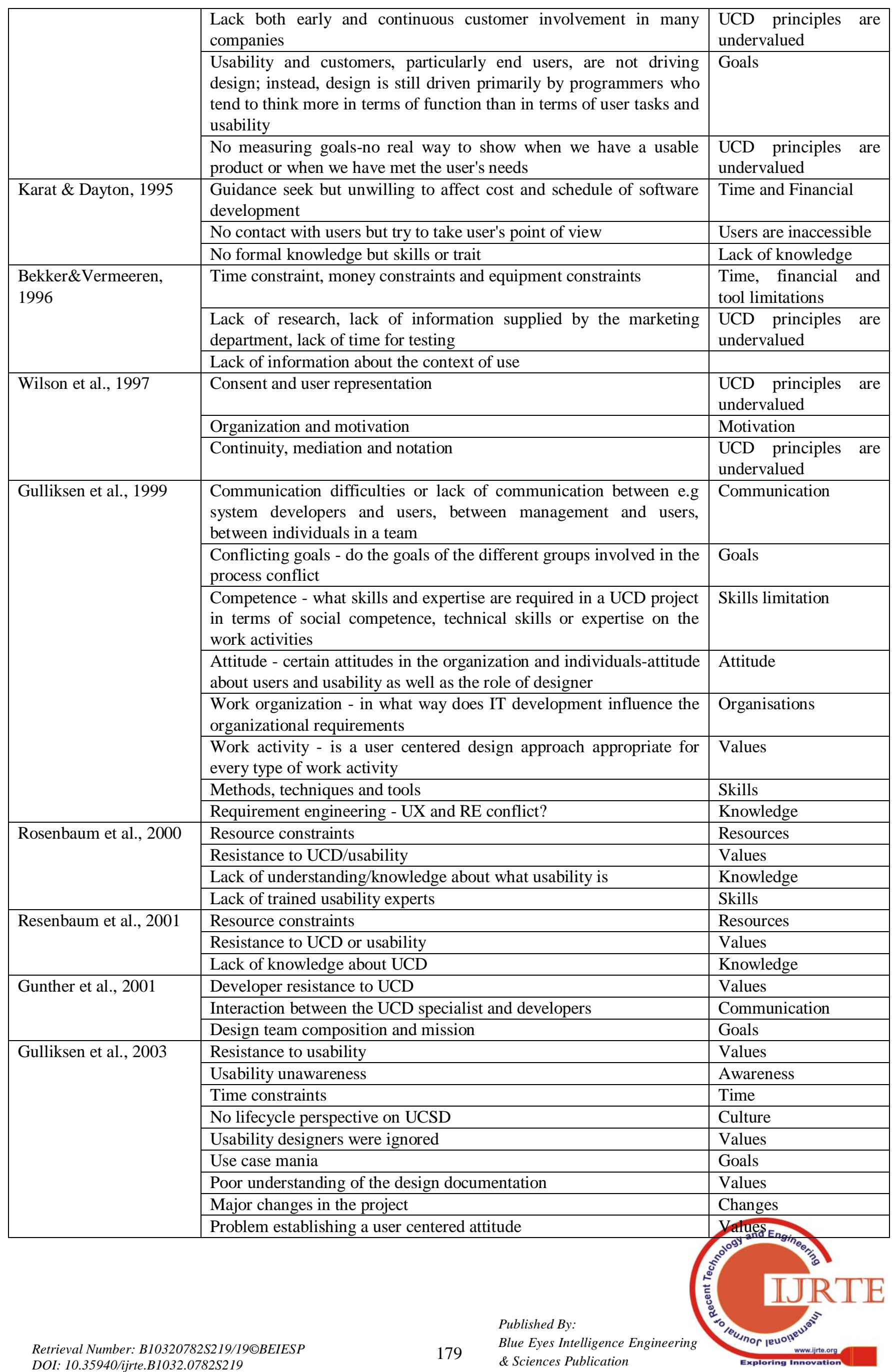


The User Centred Design (UCD) and User Experience Design (UXD) Practice in Industry: Performance Methods and Practice Constraints

\begin{tabular}{|c|c|c|}
\hline Venturi\& Troost, 2004 & Resource constraints & Resource \\
\hline \multirow[t]{3}{*}{ Rosenbaum et al., 2004} & Resource constraints & Resource \\
\hline & Resistance to UCD or usability & Values \\
\hline & Ineffective communication & Communication \\
\hline \multirow{3}{*}{ Mao et al., 2005} & Usability cannot be measured & Values \\
\hline & Development work did not have usability goals & Culture \\
\hline & Influence by management support, infrastructure and communication & Management \\
\hline Cahander et al., 2006 & $\begin{array}{l}\text { Usability terms is reduced to consistency of font and color, } \\
\text { performance and response times or customer satisfaction }\end{array}$ & Knowledge \\
\hline $\begin{array}{l}\text { Norgaard\&Hornbaek, } \\
2006\end{array}$ & Gap between academics and practitioners & Knowledge \\
\hline \multirow[t]{5}{*}{ Yi \& Yun, 2006} & Management must think UCD gives benefits to the company & Management \\
\hline & UCD must be part of business strategy & Goals \\
\hline & Usability goals as competitive analysis & Goals \\
\hline & Discussed with customer & Customer \\
\hline & Communication inside and outside company & Communications \\
\hline \multirow{3}{*}{ Gulliksen et al., 2006} & Technical nature & Technical \\
\hline & Complexity of systems development in combination of time pressure & Time \\
\hline & Support from project management, upper management and users & Management \\
\hline \multirow[t]{4}{*}{ Vukelja et al., 2007} & Software engineers don't get help from HCI professionals & Job roles \\
\hline & Limited knowledge of $\mathrm{HCI}$ & Knowledge \\
\hline & Do not make use the access to end users & Values \\
\hline & Usability tests are rare and seldom result in big changes & Skills \\
\hline \multirow[t]{2}{*}{ Bygstad et al., 2008} & $\begin{array}{l}\text { Companies express interest and concern for usability but less willing } \\
\text { to use resources with strong time and cost pressures }\end{array}$ & Cosmetics \\
\hline & Not clear usability role & Job role \\
\hline \multirow[t]{2}{*}{ Zhou et al., 2008} & Respondents may have low UCD knowledge & Knowledge \\
\hline & Doubted usability could save costs and time for product development & Values \\
\hline \multirow[t]{2}{*}{ Shackel, 2009} & $\begin{array}{l}\text { Development tenders tend to forget about the user and focus on the } \\
\text { technological artifact }\end{array}$ & Values \\
\hline & Users and managers not fully involved & Values \\
\hline \multirow[t]{3}{*}{ Chilana et al., 2011} & The role of usability has been deployed & Job roles \\
\hline & Difficult to iterate after product launching & $\begin{array}{l}\text { UCD principles are } \\
\text { undervalued }\end{array}$ \\
\hline & User feedback is not taken into consideration & Values \\
\hline Putnam \& Kolko, 2012 & Different job title different empathy & Job roles \\
\hline \multirow[t]{8}{*}{ Ardito et al., 2013} & No suitable methods & Values \\
\hline & User availability & Values \\
\hline & Developer mindset & Values \\
\hline & No problems & Values \\
\hline & Do not know & Knowledge \\
\hline & Customer Participation & Customer \\
\hline & communication between developers and designers & Communications \\
\hline & Resource constraints & Resource \\
\hline \multirow[t]{2}{*}{ Clemmensen, 2013} & $\begin{array}{l}\text { Development tenders tend to forget about the user and focus on the } \\
\text { technological artifact }\end{array}$ & Values \\
\hline & Users and managers must be fully involved & Values \\
\hline
\end{tabular}

In Table 3, early researchers investigated issues and constraints to practising UCD at organisational and individual levels (Venturi\& Troost, 2004; Marti \& Bannon, 2009). It was found that research in industry settings received low interest among researchers (Buie et al., 2010a). Hence, delaying the incorporation of good practices as there is no benchmark on how to best incorporate HCI knowledge among IT professional's practice. Vukelja et al. (2007) found the low level of HCI knowledge among software engineers alarming. They believed that it was due to poor awareness of the importance of the user interface among engineers and management, and a lack of education in HCI. UCD was not integrated in the software development process. Gulliksen and Ian (2001) concluded that fitting the UCD process into development phases was still difficult, for reasons such as lack of time, communication problems, organisational problems, bad attitudes, lack of competence or simply focusing attention on the project to keep within time and budget. 
On the other hand, studies in Sweden found that $\mathrm{HCI}$ knowledge was no longer lacking in practice, although it still lacked respect and support for usability issues (Gulliksen et al., 2001). Gulliksen and colleagues (2004) questioned the impact of the increasing attention given to usability in IT development since 1995; their survey covered usability professionals at UPA and CHI conferences in 2002 and 2003. The main issue with previous surveys is the methodological approach to the study of practice, which is dominated by the survey method. Most studies were conducted in developed countries, and their methods may not be suitable for practices in developing countries. Their findings were limited to discovering the usability methods, tools and techniques that were mostly used by usability practitioners in industry (Dillon et al., 1993; Mao et al., 2005; Ronggang et al., 2008; Ji and Yun, 2008).

Several other researchers were able to uncover constraints that enabled them to focus on effective usability practice by conducting a qualitative method(interviewing) (Gulliksen, 1999; Bak et al., 2008). Despite the plethora of authors emphasising the importance of UCD constraints, there is little variety with regards to goal formulation and the theoretical frameworks used to analyse them. However, most usability research at that time focused on what should be done, rather than what actually happens in practice. Questions about what happens, which issues matter most in practice, and their relationship to software production development and design, need urgent answers. Issues within development teams have also received lack of attention due to the constraint of researcher participation in the practice itself. Hence, this creates a gap between industry and research as a whole. In this study, designers mentioned that goals described as "flexible" or "responsive" are very difficult to reach. Marti and Bannon (2009) argued that UCD tends to ignore other design approaches, such as active user participation, in the design process. Successful UCD implementation requires the identification of appropriate HCI design and UCD processes and the integration of these processes with existing software development processes (Marti \& Bannon, 2009). The idea was later taken up in an IEEE colloquium whereby UCD techniques were proposed as a solution to ensure that users, designers and system developers designed right the first time. The important role that people in organisations play in the overall success of UCD was also highlighted (Hakiel, 1999). However, initially, the most fundamental principle of involving users in the early stage of designing any system was violated. In fact, users were always being underestimated (Holmstrom\& Sawyer, 2011).

\section{CONCLUSION AND FUTURE RESEARCH DIRECTIONS}

This research employed SLR approach to identify methods used in investigating UCD practice in industry. The same approach was utilized to find out the constraints in UCD and UXD practice in industry. 35 relevant papers were selected for the review process. The study's outcome reveals that most investigations carried out to assess UCD/UXD practice was done using surveys $(66 \%)$ followed by interviews $(29 \%)$. Low-profile usability professionals in the

development process, usability not being accepted as a key quality, usability not supporting product development time, resistance to usability, lack of awareness, and time constraints were the constraints facing UCD and UXD in practice industry. In addition, most software development studies also found constraints between developers and users. This study is limited in the sense that the electronic databases used for the search of articles were limited. Future studies will consider expanding the coverage area for the search databases.

\section{REFERENCES}

1. Ardito, C., Buono, P., Caivano, D., Costabile, M. F., Lanzilotti, R., Bruun, A., \& Stage, J. (2011). Usability evaluation: a survey of software development organisations. Paper presented at the SEKE.

2. Ardito, C., Buono, P., Caivano, D. V., Costabile, M. F., \& Lanzilotti, R. (2013). Investigating and promoting UX practice in industry: an experimental study. International Journal of Human-Computer studies.

3. Bak, J. O., Nguyen, K., Risgaard, P., \& Stage, J. (2008). Obstacles to usability evaluation in practice: a survey of software development organizations. Paper presented at the NordiHCI 2008, Lund, Sweden.

4. Bannon, L. (1991). From human factors to human actors: The role of psychology and Human-Computer Interaction studies in systems design. In J. Green \& M. Kyng (Eds.), Design at Work: Cooperative Design of Computer Systems (pp. 25-44). Hillsdale: Lawrence Erlbaum Associates

5. Borgholm, T., \& Madsen, K. H. (1999). Cooperative usability practices. Communications of the ACM, 42(5), 91-97.

6. Butler, K. A. B. (1985). Connecting theory and practice: a case study of achieving usability goals. SIGCHI Bull., 16(4), 85-88. doi: 10.1145/1165385.317472

7. Buie, E., Dray, S., Instone, K., Jain, J., Lindgaard, G. \& Lund, A. (2010). How to bring HCI research and practice closer together. Paper presented at the Proceedings of the 28th of the international conference extended abstracts on Human factors in computing systems, Atlanta, Georgia, USA.

8. Bygstad, B., Ghinea, G., \& Brevik, E. (2008). Software development methods and usability: Perspectives from a survey in the software industry in Norway. Interacting with Computers, 20(3), 375-385. doi 10.1016/j.intcom.2007.12.001

9. Chaiklin, S. (2011). Social Scientific Research and Societal Practice: Action Research and Cultural-Historical Research in Methodological Light from Kurt Lewin and Lev S. Vygotsky. Mind, Culture, and Activity, 18(2), 129-147. doi: 10.1080/10749039.2010.513752

10. Clemmensen, T., Hertzum, M., Yang, J., \& Chen, Y. (2013). Do Usability Professionals Think about User Experience in the Same Way as Users and Developers Do? In P. Kotzé, G. Marsden, G. Lindgaard, J. Wesson \& M. Winckler (Eds.), Human-Computer Interaction INTERACT 2013, Vol. 8118, Springer Berlin Heidelberg, 461-478.

11. Curtis, B., Krasner, H., \& Iscoe, N. (1988). A field study of the software design process for large systems. Communication of the ACM, 31(11), 1268-1287.

12. Dillon, A., Sweney, M., \& Maguire, M. (1993). A survey of usability evaluation practices and requirements in the European IT industry. Paper presented at the HCI'93, Cambridge.

13. Forlizzi, J., \& Ford, S. (2000). The building blocks of experience: an early framework for interaction designers. In Proceedings of the 3rd conference on Designing interactive systems: processes, practices, methods, and techniques. ACM.419-423.

14. Goransson, B., Lind, M., Pettersson, E., Sandblad, B., \& Schwalbe, P. (1986). The interface is often not the problem. SIGCHI Bull., 17(SI), 133-136. doi: 10.1145/30851.30872

15. Gould, J.D., \& Lewis, C. (1985). Designing for usability: Key principles and what designers think. Communications of the ACM, 28 , 300-311.

16. Grudin, J. (1991). Bridging the gaps between developers and users (2nd ed. Vol. 4). San Francisco: Morgan Kaufmann. 
17. Grudin, J., \& Poltrock, S. E. (1989). User interface design in large corporations: coordination and communication across disciplines. SIGCHI Bull., 20(SI), 197-203. doi: 10.1145/67450.67489

18. Gulliksen, J., Lants, A., \& Boivie, I. (1999). User centered design Problems and possibilities. A summary of the 1998 PDC \& CSCW workshop, SIGCHI Bulletin, Seattle, USA, 2-31.

19. Gulliksen, J., \& Lantz, A. (2001). Design versus design-from the shaping of product to the creation of user experiences.

20. Gunther, R., Janis, J., \& Butler, S. (2001). The UCD decision matrix: how, when, and where to sell user-centered design into the development cycle. Ovo Studios Usability Labs and Services.

21. Hakiel, S. (1999). Sufficient and necessary conditions for routine deployment of user-centred design. Paper presented at the IEEE Colloquium on Human Computer Interaction.

22. Hammond, N., Jorgensen, A., MacLean, A. , Barnard, P., \& Long, J. (1983). Design practice and interface usability: Evidence from interviews with designers. Paper presented at the Proceedings of the SIGCHI conference on Human Factors in Computing Systems, Boston, Massachusetts, United States.

23. Hashim N.L., Adamu R. (2017). Usability evaluation of mobile banking application interfaces. Journal of Engineering and Applied Sciences, Vol 12, Issue 21

24. Helander, M. G., \& Khalid, H. M. (2006). Affective and pleasurable design. Handbook of Human Factors and Ergonomics, Third Edition, 543-572.

25. Higgins, J. P. (Ed.). (2008). Cochrane handbook for systematic reviews of interventions (Vol. 5). Chichester: Wiley-Blackwell.

26. Holmstrom, J., \& Sawyer, S. (2011). Requirements engineering blinders: exploring information systems developers/' black-boxing of the emergent character of requirements. European Journal Information System, 20(1), 34-47.

27. Hussain, A., Abdullah,A., Husni, H., \& Mkpojiogu, E.O.C. (2016). Interaction Design Principles for Edutainment Systems: Enhancing the Communication Skills of Children with Autism Spectrum Disorders. Rev. Tec. Ing. Univ. Zulia. 39(8), 45-50. doi: 10.21311/001.39.8.06

28. Hussain, A., Abd Razak, M.N.F., Mkpojiogu, E.O.C. \& Hamdi, M.M.F. (2017). UX evaluation of a video streaming application with teenage users. Journal of Telecommunication, Electronic \& Computer Engineering (JTEC), 9 (2-11), 129-131

29. Hussain, A., Isam, M., \& Mkpojiogu, E.O.C. (2017). A UX assessment of a mobile recommender app for household electrical energy savings. Journal of Telecommunication, Electronic \& Computer Engineering (JTEC), 9 (2-11)

30. Hussain, A., Mkpojiogu, E.O.C., Musa, J., Mortada, S., \& Yue, W.S. (2018). Mobile Experience Evaluation of an e-Reader App. Journal of Telecommunication, Electronic \& Computer Engineering (JTEC), 10(1-10), 11-15.

31. Ibargoyen, A., Szostak, D., \& Bojic, M. (2013). The elephant in the conference room: let's talk about experience terminology. Paper presented at the CHI 2013, Paris, France.

32. Karat, J., \& Dayton, T. (1995). Practical education for improving software usability. Paper presented at the CHI'95.

33. Karat, J. (1997). Evolving the scope of user-centered design. Commun. ACM, 40(7), 33-38. doi: 10.1145/256175.256181

34. Kitchenham, B., \& Charters, S. (2007). Guidelines for performing systematic literature reviews in software engineering: School of Computer Science and Mathematics, Keele University

35. Mao, J-Y., Vredenburg, K., Smith, P. W., \& Carey, T. (2005). The state of user-centered design practice. Commun. ACM, 48(3), 105-109. doi: $10.1145 / 1047671.1047677$

36. Marti, P. \& Bannon, L. (2009). Exploring User-Centred Design in Practice: Some Caveats. Knowledge, Technology and Policy, 22(1), 7 15. doi: 10.1007/s12130-009-9062-3

37. Mayhew, D. J. (1999). The usability engineering lifecycle: a practitioner's handbook for user interface design. San Francisco, California: Morgan Kauffmann Publishers, Inc.

38. Nielsen, J. (1993). Usability engineering. San Diego: Academic Press, Inc.

39. Norman, D.A. (2010). The research-practical gap: the need for translational developers. Interaction, 17.

40. Poltrock, S. E., \& Grudin, J. (1994). Organizational obstacles to interface design and development: two participant-observer studies. ACM Transactions on Computer-Human Interaction (TOCHI), 1(1), $52-80$.
41. Putnam, C., \& Kolko, B. (2012). HCI professions: differences \& definitions. In CHI'12 Extended Abstracts on Human Factors in Computing Systems (pp. 2021-2026). ACM.

42. Putnam, C., Wozniak, K., Zefeldt, M. J., Cheng, J., Caputo, M., \& Duffield, C. (2012). How do professionals who create computing technologies consider accessibility?. In Proceedings of the 14th international ACM SIGACCESS conference on Computers and accessibility (pp. 87-94). ACM.

43. Ronggang, Z., Shengshan, H., Xiangang, Q., \& Huang, J. (2008). A survey of user-centered design practice in China. IEEE International Conference on Systems, Man and Cybernetics, 2008.

44. Rosenbaum, S., Bloomer, S., Rinehart, D., Rohn, J., Dye, J., Humburg, J., Wixon, D. (1999). What makes strategic usability fail?: lessons learned from the field. ACM Trans. Comput.-Hum. Interact., 93-94.

45. Rosenbaum, S., Wilson, C. E., Jokela, T., Rohn, J. A., Smith, T. B., \& Vredenburg, K. (2002). Usability in practice: User experience lifecycle - evolution and revolution. Paper presented at the CHI 2002, Minneapolis, Minnesota, USA

46. Rauch, T., \& Wilson, T. (1995). UPA and CHI surveys on usability processes. ACM SIGCHI Bulletin, 27(3), 23-25.

47. Salleh, N., Mendes, E., \& Grundy, J. (2010). Empirical studies of pair programming for CS/SE teaching in higher education: a systematic literature review. IEEE Transactions on Software Engineering.

48. Shackel, B., \& Day, D. L. (2009). Human-Computer Interaction whence and whitter? Interacting with Computers. doi: 10.1016/j.intcom.2009.04.004

49. Silva da Silva, T., Martin, A., Maurer, F., \& Silveira, M. (2011, 7-13 Aug. 2011). User-centered design and Agile methods: a systematic review. Paper presented at the AGILE Conference (AGILE), 2011.

50. Tullis, T. \& Albert, B. (2013). Measuring The User Experience: Collecting, Analyzing and Presenting Usability Metrics (2nd ed.): Morgan Kaufmann Publishers.

51. Venturi, G., \& Troost, J. (2004). Survey on the UCD integration in the industry. Paper presented at the NordiCHI'04, Tampere, Finland.

52. Vukelja, L., Muller, L., \& Opwis, K. (2007). Are Engineers Condemned to Design? A Survey on Software Engineering and UI Design in Switzerland. Paper presented at the INTERACT 2007.

53. Wilson, S., Bekker, M., Johnson, P., \& Johnson, H. (1997). Helping and hindering user involvement - a tale of everyday design. Paper presented at the $\mathrm{CHI} 97$.

54. Zhao, F., Collier, A., \& Deng, H. (2014). A multidimensional and integrative approach to study global digital divide and e-government development. Information Technology \& People, 27(1), 38-62. 